\title{
Innovative Water-reduced Injection Grouts For The Stabilisation Of Wall Paintings In The Hadi Rani Mahal, Nagaur, India: Design, Testing and Implementation
}

Chiara Pasian, Department of Conservation and Built Heritage, University of Malta, Malta

Charlotte Martin de Fonjaudran, Private conservator, Paris, France

Amarilli Rava, Conservation of Wall Paintings Department, The Courtauld Institute of Art, London, UK

\section{Abstract:}

The design and evaluation of site-specific injection grouts for the stabilisation of delaminated wall paintings is often challenging to perform in situ, due to constraints such as time, availability of materials and reliable testing procedures. In this research, a rigorous design and testing methodology, which includes the development of a new adhesion test, was adopted on site for the development of injection grouts to be used in water-sensitive situations. Water reduced mixtures were obtained by partly substituting it with ethanol. Previous research (Pasian et al. 2018) demonstrated in the laboratory the potential suitability of water-ethanol grouts. In the present paper, water-reduced grouts were designed, tested and applied on site for the first time.

Keywords: injection grout, design, field testing, water-reduced, ethanol

\section{INTRODUCTION}

\subsection{Design and testing of injection grouts}

Wall paintings are multi-layered, highly complex porous systems, for which the-immovable-support belongs to the structure or building itself. Wall paintings may suffer from delamination between plaster layers. This deterioration phenomenon can be stabilised through injection grouting, introducing a compatible adhesive material with bulking properties [1]. Grouting is irreversible and grouted areas may be difficult to retreat [2:472], therefore physico-chemical compatibility with the original materials is paramount, and the grout design should be tailored to specific deterioration phenomena.

The design of site-specific grouts is often challenging to perform in situ, due to constraints such as lack of resources (e.g. time and availability of materials), and reliable analyses and testing procedures. No standards for testing of non-structural lime-based injection grouts are currently internationally agreed, although research on this has been carried out ([3], [4], [5]). Field testing procedures have been proposed and compared to laboratory procedures [3], however, there is a lack of publications describing a methodology for the design and testing of grouts formulated ad hoc on site. In this research, a rigorous design and testing methodology was adopted on site for the development of injection grouts with reduced water content, suitable for use with plasters highly contaminated with soluble salts.

\subsection{The Loggia of the Hadi Rani Mahal, Ahhichatragarh fort and palace complex of Nagaur, India}

The reduced-water grouting intervention was carried out in the Loggia of the Hadi Rani Mahal, in the Ahhichatragarh fort and palace complex of Nagaur, Rajasthan, India.

Founded in the $4^{\text {th }} \mathrm{c}$., the complex is today largely an $18^{\text {th }} \mathrm{c}$. Rathore Rajput construction with Mughal influences [6:18], built and decorated under the rule of the maharaja Bakhat Singh (1725-50). In the Hadi Rani Mahal, the most important painted palace, an open Loggia on the ground floor marks the division between the maharaja's public and private sphere. It is magnificently decorated with wall paintings 
depicting winged female figures and birds on the ceiling panels, and fighting elephants on the walls [7:31, 47]. The palace is built with local red sandstone blocks joined with a gypsum mortar, covered with two to four layers of lime-based plaster. The coarse plaster contains brickdust and sand, while the fine, highly polished upper plaster layer contains white marble powder (araish technique) ${ }^{1}$. The use of organic additives in plasters such as tree resin and sugar cane, currently employed by local masons [7:311], is also reported in historic texts [8:103-4].

The fort has a complex physical history [7:59], including historic water infiltration, widespread and unstable plaster delamination and past conservation interventions (Fig.1). The Loggia underwent replacement of ceiling panels ${ }^{2}$ due to their collapse, and filling of losses with a gypsum-based material. The secondary support presents severe salt crystallisation problems, especially where water infiltration had been extensive. The Loggia is exposed to highly fluctuating and uncontrollable environmental parameters, which exacerbate cycles of salt crystallisation and deliquescence.

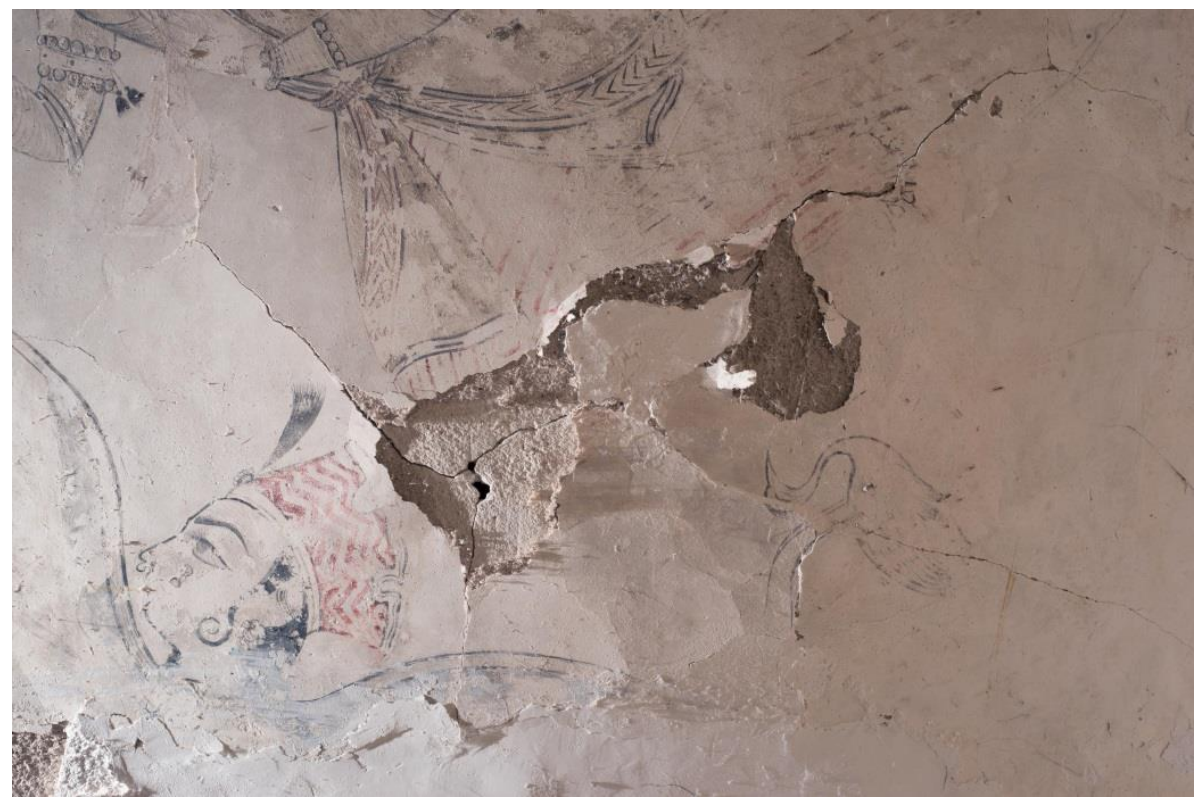

Fig.1: Unstable deformed delamination on the ceiling of the Loggia of the Hadi Rani Mahal (Ahhichatragarh fort and palace complex of Nagaur, India); raking light (CThe Courtauld Institute of Art, 2015)

\section{METHODOLOGY: GROUTS DEVELOPMENT, TESTING AND IMPLEMENTATION}

In conservation, an appropriate methodology involves an incremental and iterative approach to problemsolving [9]. Starting from the knowledge of original materials and technology, it is crucial to understand the problem, and from there set general and site-specific performance criteria for the injection grout to be designed. Grout components are selected on the basis of their physico-chemical compatibility with the original materials. In the field, where resources such as time, availability of materials and reliable laboratory testing procedures are often lacking, a simple but meaningful testing programme needs to be

\footnotetext{
${ }^{1}$ Such Rajasthani technique, which flourished in the $19^{\text {th }}$ c., includes from 2 to 5 plaster layers; the araish plaster is the final polished layer. Lime and brick aggregates (surkhi) are present in the intermediate layer. Lime, brick and sand aggregates in the bottom layer(s) applied onto the masonry. Organic additives are present throughout ([7:311]; see also http://www.unescobkk.org/fr/culture/wh/asia-pacific-heritage-awards/previous-heritage-awards-2000-

2013/2000/technical-brief/araish/, consulted on 13 January 2020). The tradition is orally transmitted from mason to mason, therefore variations in general in the technique and in the preparation of the plasters may be encountered.

${ }^{2}$ In the 1990s architectural restoration by the Mehrangarh Museum Trust.
} 
developed, starting with properties which are paramount for the grout to fulfil and faster to assess, reducing the number of possible grout mixtures for properties requiring more complex testing methodologies. If necessary, the formulation needs to be modified and tested again until suitable, following an iterative process (Fig.2).

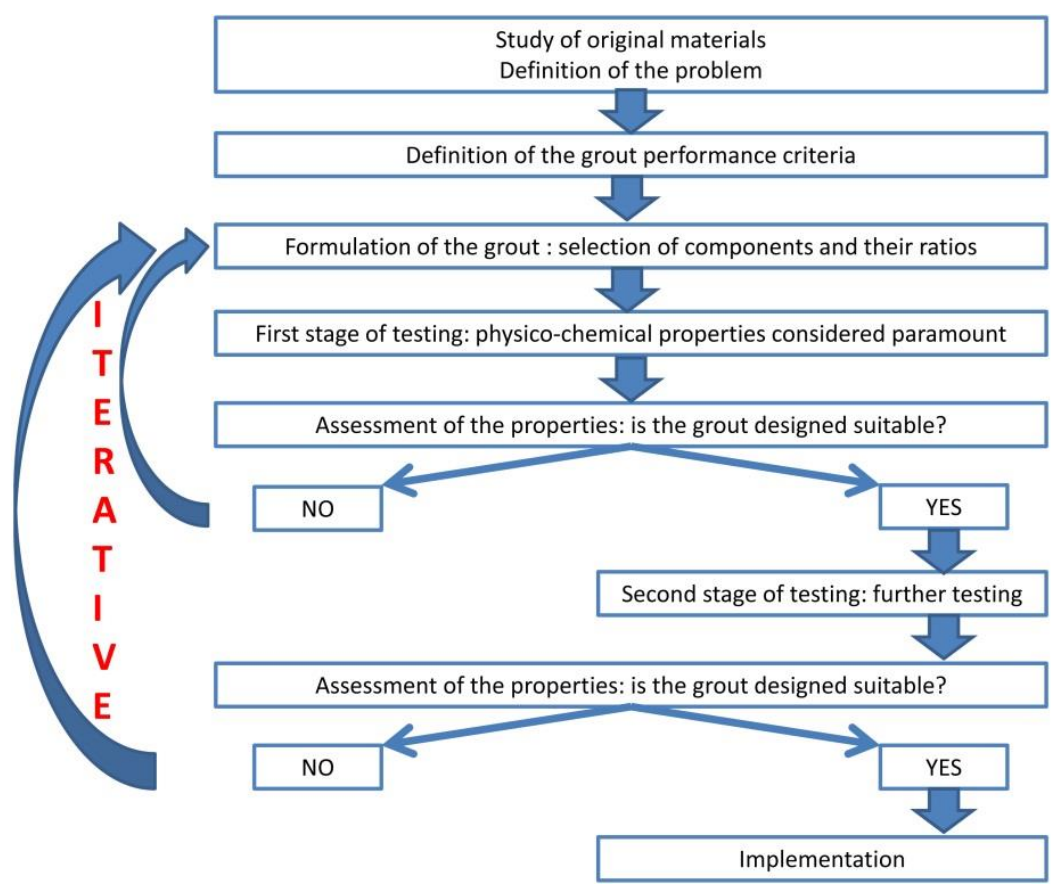

Fig.2: Methodology for grout development and testing

\subsection{Definition of the problem and of the grouting performance criteria}

Condition assessment of the Loggia revealed extensive areas of unstable delamination occurring at different locations within the plaster stratigraphy with salt efflorescence both on the surface and inside the delamination, and salt-forming ions throughout the stratigraphy. Two types of delamination were identified:

1. thick and deformed (up to $50 \mathrm{~mm}$ ), typically between the stone support and the coarse plaster;

2. thin (up to $5 \mathrm{~mm}$ ), typically between the coarse and the araish plaster.

In general, any non-structural injection grout to fulfil its function and be effectively used should meet several long-term and short-term performance criteria, including (Table 1, [1]):

Table 1: Long-term and short-term grouts performance criteria

\begin{tabular}{|c|c|}
\hline Long-term performance criteria & Short-term performance criteria \\
\hline $\begin{array}{l}\text { - } \text { minimal shrinkage after setting } \\
\text { - } \text { porosity, water vapour permeability and } \\
\text { hygrothermal behaviour similar to the original } \\
\text { plasters } \\
\text { - mechanical strength similar to or lower than that } \\
\text { of the original plasters } \\
\text { - low dry density } \\
\text { - good adhesion }\end{array}$ & $\begin{array}{ll}\text { - } & \text { low wet density } \\
\text { - } & \text { good injectability } \\
\text { - } & \text { good flow } \\
\text { - low water content and release }\end{array}$ \\
\hline
\end{tabular}


Some performance criteria may be more critical depending on site-specific characteristics and deterioration phenomena. In this study, the focus was placed on the following (Table 2), according to the different type of delamination on site.

Table 2: Site-specific grouts performance criteria

\begin{tabular}{|l|l|}
\hline \multicolumn{2}{|l|}{ Site-specific performance criteria } \\
\hline $\begin{array}{l}\text { Thick and deformed delamination between } \\
\text { stone and coarse plaster (grout G) }\end{array}$ & $\begin{array}{l}\text { Thin delamination between coarse and araish } \\
\text { plaster (grout MG) }\end{array}$ \\
\hline - $\begin{array}{l}\text { adhesion, especially for horizontal } \\
\text { surfaces where the grout needs to bear } \\
\text { the weight of the plasters }\end{array}$ & $\begin{array}{l}\text { - good injectability and flow } \\
\text { low water content, for plasters highly } \\
\text { - low wet and dry density versus required } \\
\text { bulking properties to fill large voids } \\
\text { good flow, especially for horizontal } \\
\text { surfaces } \\
\text { low water content, for plasters highly } \\
\text { contaminated with soluble salts }\end{array}$ \\
\end{tabular}

\subsection{Formulation of the grouts: materials and methods}

All the grout formulations were composed of slaked lime as the binder, brickdust (both used for the original coarse plaster) and borosilicate glass microspheres. Brickdust acts as a filler and has been found to have a pozzolanic effect in the original plaster; it allows the development of strength through pozzolanic reaction with calcium hydroxide [10:414]. Glass microspheres improve injectability and flow, and add bulking properties while maintaining low density [11:79]. Brickdust and quartz sand were selected for grout $G$ (thick delamination). Quartz sand was used to improve packing geometry and cohesion, and to reduce shrinkage [12]. Brickdust and marble dust (present in the araish plaster) were selected for grout MG (thin delamination). All materials, apart from the glass microspheres, were sourced locally.

Different formulations were designed based on the following variables:

- particle size of aggregates: considering that polydispersity (i.e. the range of the particle-size distribution) with a wide span improves packing geometry and decreases viscosity [13], therefore enhancing flow, aggregates were mixed based on different particle size but still forming overall a full granulometric curve (ex. brickdust $<125 \mu \mathrm{m}+$ quartz sand $125-250 \mu \mathrm{m}$; marble dust $<125 \mu \mathrm{m}+$ brickdust $125-250 \mu \mathrm{m})$;

- amount of aggregates: the volume fraction [13] was varied depending on how this had an influence on cohesion, shrinkage and flow;

- type and amount of additives:

- to improve adhesion: whisked ovalbumin also increasing porosity and therefore decreasing dry density [12], an acrylic polymer (Plextol $\mathrm{B} 500^{\circledR}$ ) and gum Arabic (tree resin is reported to be used in the original plaster, [7:311]);

- to counteract shrinkage: aluminium powder, which reacts with lime developing hydrogen ${ }^{3}$ and providing grout expansion [14] thus leading to higher porosity (air pores percentage subsequently

\footnotetext{
${ }^{3} \mathrm{Ca}(\mathrm{OH})_{2}+2 \mathrm{Al}+6 \mathrm{H}_{2} \mathrm{O} \rightarrow \mathrm{Ca}^{++}+2 \mathrm{Al}(\mathrm{OH})_{4}{ }^{-}+3 \mathrm{H}_{2}[14]$.
} 
measured in the laboratory) ${ }^{4}$ and lower dry density. Aluminium powder was added to achieve minimal expansion, aiming to counteract shrinkage exacerbated by the dry ambient environment (maximum $\mathrm{T} 40^{\circ} \mathrm{C}$ and minimum $\mathrm{RH} 20 \%$ when grouting was performed);

- type and amount of suspension medium: due to severe plaster contamination with soluble salts, water-ethanol was selected as the suspension medium. Grouts prepared with water-ethanol in the laboratory have shown suitable performance $[5,12]$ and reduced salt mobilisation in the substrate compared to water-based grouts [15]. However, testing revealed that the presence of ethanol delays and inhibits the aluminium-calcium hydroxide reaction, hindering its expansion effect. ${ }^{5}$ This factor will be relevant in the decision making (see Section 2.5).

\subsection{First stage of testing}

A first stage of testing focused on the following performance criteria:

- Grout $\mathrm{G}$ (thick delamination): shrinkage, adhesion, expansion, wet and dry density, flow

- Grout MG (thin delamination): shrinkage, adhesion, injectability, flow

Testing procedures are described below. All the tests have been performed in situ.

\section{Shrinkage}

$50 \mathrm{~mL}$ grout was injected in pre-wetted plaster cups [3:83-85] simulating the original coarse plaster. The cups were covered with discs of the same plaster to simulate the semi-closed porous delamination. Shrinkage was assessed at the surface [3:85], but also in depth, excavating the set grout with a spatula, and observing the grout adhesion to the cup wall at 10 and $30 \mathrm{~mm}$ depth. Grouts needed to show no shrinkage (and therefore good adhesion) at the surface and in depth.

\section{Expansion (and bleeding)}

$50 \mathrm{~mL}$ grout was injected in a syringe placed vertically without the syphon, its exit blocked with tape. The syringe was covered with cling film to prevent evaporation of the suspension medium. The volume increase of the grout (expansion) was monitored at time intervals of $1 \mathrm{~min}$ for $5 \mathrm{mins}$ and calculated as a percentage of the grout's initial volume. The separation of the liquid from the solid (bleeding), when occurring, was recorded and calculated. Both grouts needed to show no bleeding, and grout $\mathrm{G}$ an expansion up to $2 \%{ }^{6}$

\section{Wet and dry density}

\footnotetext{
${ }^{4}$ Porosity was tested in the laboratories of the Institute of Materials and Constructions of the University of Applied Sciences and Arts of Southern Switzerland (SUPSI), following the standard SIA 262/1:2003. The control grout (without aluminium powder) has the following porosity: $n=44.39 \%, U_{E}=37.53 \%, L P=6.86 \%$, where $n$ is total porosity, $U_{E}$ is capillary porosity and $L P$ is air pores percentage. The same grout with addition of aluminium powder $(0.15 \% \mathrm{w} / \mathrm{V}$, weight to the total volume of the grout) has the following porosity: $n=52.63 \%, U_{E}=37.41 \%, L P=15.22 \%$, resulting in an overall higher porosity, with an air pores percentage ca. 8 percentage points higher than the one of the control.

${ }^{5}$ The reason is subject to further research.

${ }^{6}$ The $2 \%$ expansion was desired for grout $\mathrm{G}$ for the following reason: grouts without expansion showed shrinkage (exacerbated by the dry ambient environment) and therefore poor adhesion; considering the thickness of the delamination and the amount of material to be injected, expansion was sought to counteract shrinkage. This was not necessary for grout MG: such grout was not visibly shrinking in the thin thickness it needed to address, therefore expansion was judged not to be crucial. $2 \%$ has been identified as an adequate expansion to counteract shrinkage and small enough not to lead to mechanical tension.
} 
$50 \mathrm{~mL}$ grout was injected in a Petri dish and weighed (wet weight). The sample was weighed over time until the weight variation was $<0.05 \%$ in 24 hours (dry weight). Wet and dry density was calculated $(\mathrm{m} / \mathrm{V})$. Grouts with the lowest wet and dry density were preferred.

Flow

$10 \mathrm{~mL}$ grout was injected through a syringe and let flow on a sandstone wall on site. The speed of flow was calculated (length of the extruded grout to time of flow ratio, in mm/s: quick $>25 \mathrm{~mm} / \mathrm{s}$, fair $15-25 \mathrm{~mm} / \mathrm{s}$, slow $<15 \mathrm{~mm} / \mathrm{s}$ ); length, homogeneity and thickness of the extruded grout were observed. Grout $\mathrm{G}$ needed to show a fair speed of flow, while grout MG a quick one, with both keeping a homogenous, bodied drip.

\section{Injectability}

The grout was injected through a syringe with a $2.7 \mathrm{~mm}$ diameter catheter (for grout G) or a needle G14 (1.6 mm diameter, for grout MG) applied to its tip. ${ }^{7}$ The grout was classified as difficult ( $<10 \mathrm{~mL}$ ), fairly (10$15 \mathrm{~mL}$ ) or easily $(>15 \mathrm{~mL}$ ) injectable according to how much material was passing through the catheter or needle in 5 seconds. The grouts needed to be easily injectable.

Results were compared and grouts which performed best in all the tests were selected for a second stage of testing.

\subsection{Second stage of testing}

Further testing of grouts was focused on capillary absorption and adhesion ('sandwich' test). Testing procedures are described below. Capillary absorption was important to test particularly for grout G, prepared with aluminium powder, to check if the macro pores (air pores) developed were connected or isolated, and if the grout still allowed water passage.

\section{Capillary absorption}

Initially, a drop of deionised water was placed on the surface of grout samples (cylinders: $50 \mathrm{~mm}$ diameter, $20 \mathrm{~mm}$ height, prepared on a porous substrate-plaster) and its absorption observed. Test RILEM II.6 [16] was then performed to determine the capillary absorption ( $W_{60 s}$, weight to surface ratio at 60 seconds). The capillary front was followed on the side of the samples to assess the liquid speed of diffusion. Grouts needed to easily allow water passage (i.e. $W_{60 \mathrm{~s}}=0.2-0.3 \mathrm{~g} / \mathrm{cm}^{2}$ ).

\section{'Sandwich' test}

A 'sandwich' test was developed to test adhesion of the grout set between porous layers. This test is the ad hoc field version of the laboratory 'sandwich' test [17]. Plaster discs (100 mm diameter) were prepared simulating coarse (height $20 \mathrm{~mm}$ ) and araish (height $5 \mathrm{~mm}$ ) plasters. The discs were glued onto plywood squares, on which a canvas bag was attached to incrementally add weight to the system. Grout $\mathrm{G}$ was injected on coarse plaster discs, the system was attached to the underside of a sandstone slab placed horizontally (to simulate a horizontal delamination) and let set for 21 days (Fig.3). Grout MG was injected on araish plaster discs (Fig.4), and the system was attached to coarse plaster discs. After the grout had set (21 days), the system was placed in a position which simulated a horizontal delamination. Weights of $100 \mathrm{~g}$

\footnotetext{
${ }^{7}$ Catheters and needles for delivery were chosen based on access points for injection and the thickness of the delamination in which the grouts needed to flow.
} 
were incrementally added to the canvas bag until the system failed. The rupture was qualitatively evaluated: failure at the interface between materials gives information about actual adhesion; failure in the middle of the grout thickness indicates grout cohesion. The bond or cohesive strength were then calculated with $\sigma=F / A$ (where $\sigma$ is the tension, $F$ the applied force and $A$ the area where the rupture occurs). $A$ rupture in the middle of the grout is preferable, as it indicates that the grout-stone/grout-plaster bond strength is higher than the grout cohesion, and that the grout cohesion is lower than that of the 'original' materials.

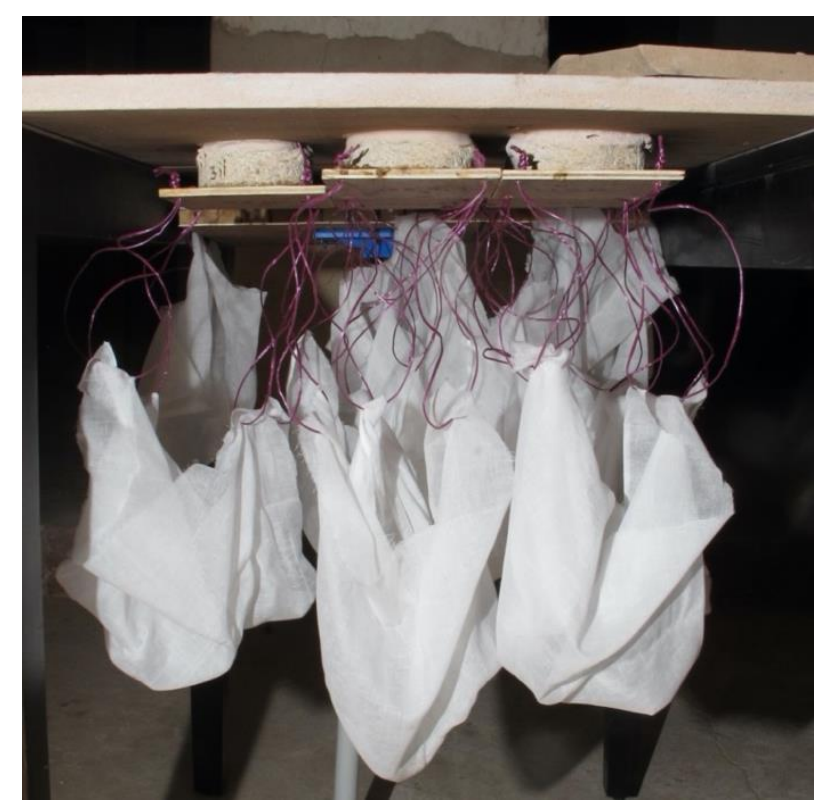

Fig.3: 'Sandwich' test for grouts $\mathrm{G}$ (stone-coarse plaster delamination)

(@The Courtauld Institute of Art, 2016)

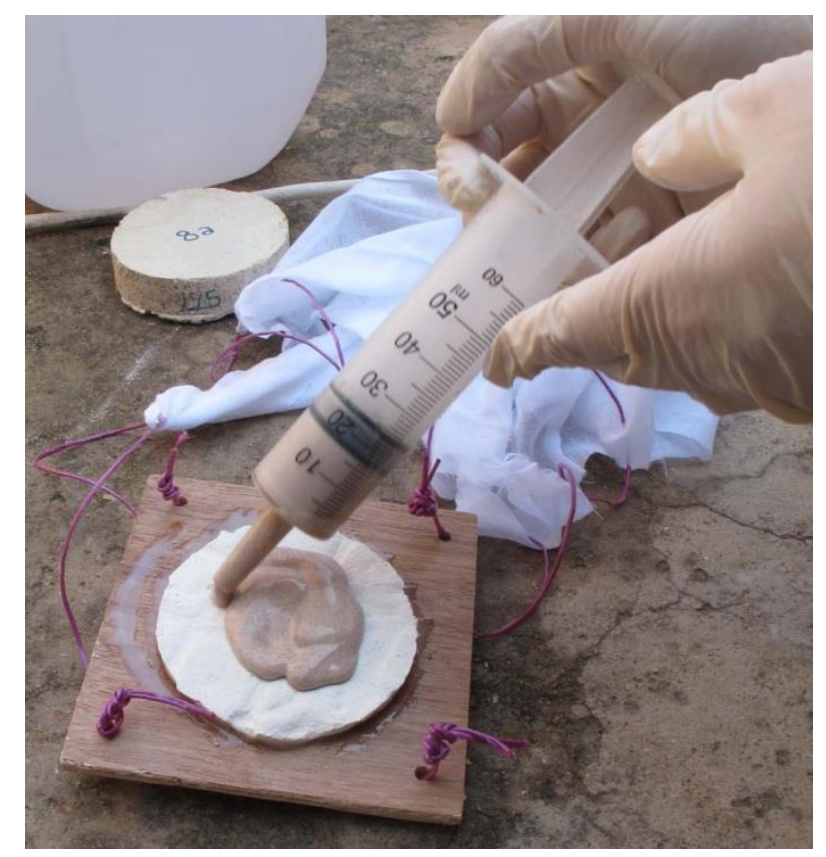

Fig.4: 'Sandwich' test preparation for grouts MG (coarse-araish plaster delamination)

(@The Courtauld Institute of Art, 2016) 


\subsection{Assessment, discussion and implementation}

- Thick delamination - Grout G:

Grouts prepared with $100 \%$ water and $50 \%$ water- $50 \%$ ethanol, with aluminium powder and without adhesives performed well, including in the 'sandwich' test; the system always failed in the middle of the grout when adhesives were not present (i.e. the adhesion was higher than the grout cohesion; cohesion was higher than adhesion when adhesives were present). The water-ethanol grout, however, had a slightly higher density (because of a higher amount of quartz sand required to counteract shrinkage) and a delayed and more limited expansion compared to the water-based grout. An area of a painted ceiling in the Loggia, with imminent risk of loss due to unstable and deformed delamination, was selected for initial implementation and evaluation. Low dry density was deemed paramount due to gravity and anticipated amount of grout required to re-establish adhesion. Therefore, water-based grout $\mathrm{G}$, with a faster and higher expansion, good bulking properties and lower density compared to the water-ethanol one, was considered safer to implement in this particular area (Fig.5). Efflorescence was removed from the surface in the unstable area to grout, and efflorescence and plaster microcores were taken from a close stable area. They were analysed with ion test strips. In both areas, sulphates, chlorides and potassium were detected at the surface; in the stable area, such ions were detected also close to the surface (up to $6 \mathrm{~mm}$ in depth). Within the stratigraphy (up to $18 \mathrm{~mm}$ in depth) primarily sulphates and some nitrates were identified. Salt recrystallisation on the surface was reduced through the use of a multi-layer clay ${ }^{8}$-based absorbent press system, also securing the painting [18:213]. The ion content in the clay was verified with ion test strips after the intervention, after having removed the press; sulphates, nitrates, chlorides and potassium were identified, as in the plaster. The area was monitored for 14 days after the intervention and no efflorescence appeared on the surface.

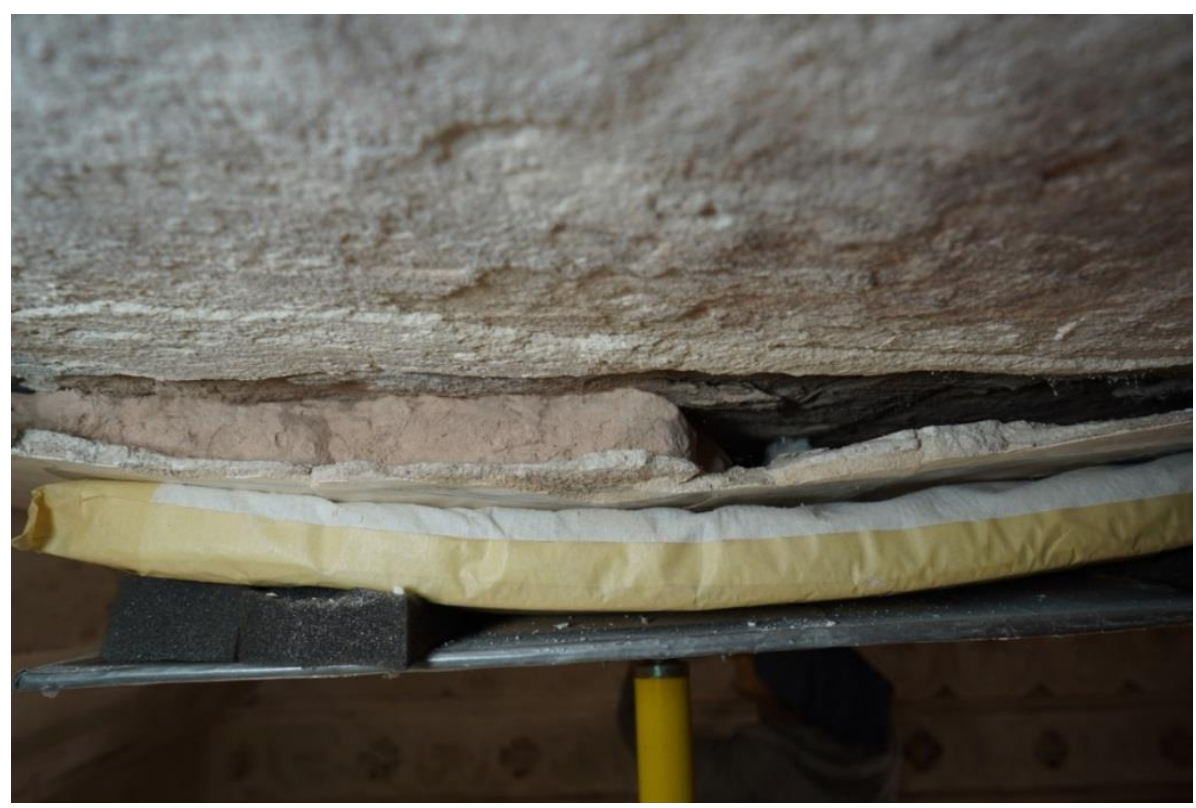

Fig.5: Delaminated area partially filled with grout $\mathrm{G}$, showing good adhesion, with multi-layer absorbent press (CThe Courtauld Institute of Art, 2016)

\footnotetext{
${ }^{8}$ The clay used was Pangel S9 (supplier: Tolsa), which is composed of highly purified sepiolite, micronised to provide high pseudoplasticity; such clay is stable at high electrolyte concentration, therefore in presence of high amount of soluble salts (http://www.tolsa.com/aditivos/wp-content/uploads/sites/5/PANGEL-S9-EN-201409.pdf, consulted on 17 January 2020).
} 
- Thin delamination - Grout MG:

Grouts without adhesives performed well in the 'sandwich' test (cohesion rather than adhesion failure). Grout expansion and low density for thin delaminations were judged less critical. A water-ethanol solution was therefore preferred for this grout, though limiting the amount of ethanol to $30 \%$ compared to previous studies (up to $85 \%$ in [12]) due to environmental conditions on site. ${ }^{9}$ With $30 \%$ ethanol, the amount of water was sufficient for the chemical reactions to occur [12], mobilisation of soluble salts was reduced and good flow and injectability maintained.

\section{CONCLUSIONS}

Grouts with reduced water content for salts-contaminated plasters were designed and tested on site, and implemented in the Loggia of the Hadi Rani Mahal (Nagaur, India) following a rigorous methodology adapted to site constraints and specific deterioration phenomena. The reduction of water was performed as far as possible according to the climate conditions on site (up to $30-50 \%$ ethanol). For the thin delamination a reduced-water grout was implemented (grout MG with $30 \%$ ethanol). For the fragile test area with a thick delamination, the water-based grout $\mathrm{G}$ was chosen because of its lower density and higher expansion compared to the water-ethanol-based grout. However, it was possible to use the reduced-water grout G (50\% water-50\% ethanol) in other areas of the Loggia with high salt activity where the delamination was less thick and where the lowest possible density was not a primary requirement (for instance, on vertical surfaces).

\section{ACKNOWLEDGMENTS}

The Courtauld Institute of Art has worked to preserve the wall paintings of the Ahhichatragarh fort and palace complex of Nagaur since 2005, in partnership with the Mehrangarh Museum Trust. We are grateful to the Leon Levy Foundation who supported the project at the Hadi Rani Mahal. The late Professor Sharon Cather had a profound impact on conservation worldwide, and we are grateful to her and Professor David Park for their guidance in the conservation project at the fort of Nagaur. Thanks are due to Sarah-Jane Fox and Yang Chen for the testing carried out on grout MG. We would like to thank Dr Christian Paglia for access to the laboratory of the Institute of Materials and Constructions (IMC) at the University of Applied Sciences and Arts of Southern Switzerland (SUPSI) to carry out the porosity test.

\section{REFERENCES}

[1] Griffin, I. 2004. Pozzolanas as Additives for Grouts: An Investigation of their Working Properties and Performance Characteristics. Studies in Conservation, 49(1): 23-34. doi:10.1179/sic.2004.49.1.23.

[2] Rickerby, S., Shekede, L., Fan, Z., Tang, W., Qiao, H., Yang, J. \& Piqué, F. 2010. Development and Testing of the Grouting and Soluble-Salts Reduction Treatments of Cave 85 Wall Paintings. In: N. Agnew, ed. Proceedings of the Second International Conference on the Conservation of Grotto Sites, Mogao Grottoes, Dunhuang, Conservation of Ancient Sites on the Silk Road, People's Republic of China, June 28-July 3, 2004. Los Angeles: The Getty Conservation Institute, pp. 471-79. doi:10.1016/j.nano.2009.09.005

\footnotetext{
${ }^{9}$ Due to the high ambient temperature and fast evaporation rate, a suspension medium with $>30 \%$ ethanol reduced injectability and flow and caused higher shrinkage.
} 
[3] Biçer-Șimșir, B. \& Rainer, L. 2013. Evaluation of Lime-Based Hydraulic Injection Grouts for the Conservation of Architectural Surfaces - A Manual of Laboratory and Field Test Methods. Los Angeles: The Getty Conservation Institute

[4] Pasian, C., Padovnik, A., Piqué, F. \& Jornet, A. 2016. Repeatability and reproducibility in measuring injection grouts properties: Three grouts, two operators. In: J. Papyianni, M. Stefanidou, V. Pachta, ed. Proceedings of the 4th Historic Mortars Conference (HMC 2016), Santorini, Greece, 10-12 October 2016. Thessaloniki: Laboratory of Building Materials, Department of Civil Engineering, Aristotle University of Thessaloniki, pp. 598-605.

[5] Pasian, C., Piqué, F., \& Jornet, A. 2017a. Non-structural Injection Grouts with Reduced Water Content: Changes Induced by the Partial Substitution of Water with Alcohol. Studies in Conservation, 62(1): 43-54. doi:10.1179/2047058415Y.0000000022.

[6] Tillotson, G. 2010. Nagaur: a garden palace in Rajasthan. Jodhpur: The Mehrangarh Museum Trust.

[7] The Courtauld Institute of Art. 2016. Leon Levy Foundation - Nagaur Conservation Programme. Phase 5: January - February 2016. Project Data 2016. Unpublished report. London: The Courtauld Institute of Art, University of London.

[8] Agrawal, O.P. 1969. A Study in the Techniques of Indian Wall Paintings. ICOM Committee for Conservation proceedings : Amsterdam, 1969. Volume 1-69/3.

[9] Cather, S. 2006. Trans-technological Methodology: Setting Performance Criteria for Conserving Wall Paintings. In: R. Mazzeo, ed. Proceedings of the International Seminar 'Diagnosis, Conservation and Restoration of Far Asian Mural Paintings: When East and West Encounter and Exchange', Ravenna, Italy, 28-29 May 2004. Ravenna: Angelo Longo Editore, pp. 89-95.

[10]Lea, F.M. 1970. The chemistry of cement and concrete. 3rd edition. Edward Arnold Publishers Ltd.

[11] Pasian, C. 2017. Non-structural lime-based injection grouts with reduced water content for decorated surfaces. PhD Thesis. The Courtauld Institute of Art.

[12]Pasian, C., Secco, M., Piqué, F., Artioli, G., Rickerby, S. \& Cather, S. 2018. Lime-based Injection Grouts with Reduced Water Content: An Assessment of the Effects of the Water-reducing Agents Ovalbumin and Ethanol on the Mineralogical Evolution and Properties of Grouts. Journal of Cultural Heritage, 30: 70-80. doi:10.1016/j.culher.2017.10.003.

[13]Duffy, J. 2015. Controlling Suspension Rheology: The Physical Characteristics of Dispersed Particles Have a Large Impact on Overall Rheological Properties. Chemical Engineering, 122(1): 34-39.

[14]Botticelli, G., Matteini, M., Moles, A., \& Lanterna, G. 1984. A mineral expansive material for readhesion operations on mural paintings. In: P. L. Parrini, ed. Proceedings of the Symposium 'Scientific Methodologies Applied to Works of Art', Florence, Italy, 2-5 May 1984. Florence: Montedison Progetto Cultura, pp. 177-179.

[15]Pasian, C., Piqué, F., Riminesi, C., \& Jornet, A. 2017b. How not to bother salts while grouting. In: S. Laue, ed. Proceedings of the 4th International Conference on Salt Weathering of Buildings and Stone Sculptures (SWBSS 2017), Potsdam, Germany, 20-22 September 2017. Potsdam:

Fachhochschule Potsdam, pp. 158-167.

[16]RILEM. 1978. Test $n^{\circ}$ II.6 Water absorption coefficient (capillarity). In: Proceedings International Symposium Deterioration and Conservation of Stone Monuments (UNESCO-RILEM) - (1.1 à 111.6), Paris, 1978, pp. 133-136.

[17]Pasian, C., Piqué, F., Jornet, A., \& Cather, S. 2019. A 'Sandwich' Specimen Preparation and Testing Procedure for the Evaluation of Non-Structural Injection Grouts for the Re-Adhesion of Historic Plasters. International Journal of Architectural Heritage, doi:10.1080/15583058.2019.1626513. 
[18]Martin de Fonjaudran, C., Tringham, S., \& Bogin, S. 2012. The Sheesh Mahal at Nagaur Fort, Rajasthan, India. Conservation and Training Programme 2007-2011. Final Report \& Project Data. Unpublished report. London: The Courtauld Institute of Art, University of London. 